\title{
Applicability of artificial bee colony algorithm for nurse scheduling problems
}

\author{
Kadir Buyukozkan \\ Industrial Engineering Department, Karadeniz Technical University, \\ Kanuni Campus, 61080, Trabzon, Turkey
}

\author{
Ahmet Sarucan \\ Industrial Engineering Department, Selçuk University, \\ Alaaddin Keykubat Campus, 42000, Selçuklu/Konya, Turkey \\ E-mail: sarucan@selcuk.edu.tr \\ www.selcuk.edu.tr \\ Received 15 December 2012 \\ Accepted 1 July 2013
}

\begin{abstract}
This paper describes the first Artificial Bee Colony (ABC) Algorithm approach applied to nurse scheduling evaluated under different working environments. For this purpose, the model has been applied on a real hospital where data taken from different departments of the hospital were used and the schedules from the model were compared with the existing schedules. The results obtained indicated that the proposed model exhibits success in solving the nurse scheduling problems in hospitals.
\end{abstract}

Keywords: Artificial bee colony algorithm, nurse listing, nurse scheduling, task assignment

\section{Introduction}

Personnel scheduling, aims at satisfying appropriate labor needs of enterprises for their sustainable business. The procedure has been subjected in literature as following different names; labor scheduling, worker scheduling, shift scheduling, task assignment, crew scheduling and crew planning

Health sector is an important part of service industry. Service presented in this sector contains operations in patient's medical examination processes. Doing the work incorrectly and not at its time, in the other words not to present the service as needed, may cause irreversible worse situations. Because of that, service quality in health sector bears special importance. All physical conditions must be exact and planned correctly to improve service quality in health sector.

One of the most important conditions in any well functioning health enterprise is employees with enough knowledge and ability. In this case, personnel scheduling studies in health sector becomes more important than in other service sector and is being subject in academic studies more than others.

Controlling all solution points for the solution of the NP-Hard problems with wide solution spaces like nurse scheduling problems is not feasible in an acceptable time, even with today's technology. Heuristic methods control some of the points in solution space with respect to several rules and can find an acceptable solution for the problem in a short time period. In last terms, numerous studies with heuristic methods prove its 
success and reliability on this subject. Besides these features, another important advantage of heuristic methods is that, it is not hard to adapt and model it for different problem types.

Meta-heuristic methods used in literature for the nurse scheduling problem are; Genetic Algorithm, Simulation, Tabu Search, Shifting Neighbor Search and hybrid algorithms that combined different solving models.

Valouxis and Housos ${ }^{1}$, Burke et al. ${ }^{2}$, Burke et al. ${ }^{3}$, Li et al. ${ }^{4}$, suggest hybrid algorithms for nurse scheduling. Ref. 1 used Integer Linear Programming with Local Search model and Tabu Search algorithm together. Ref.2 hybridized Tabu search heuristic with Genetic algorithm. Ref. 3 used Heuristic Ordering and Shifting Neighbor Search together. Ref. 4, used goal programming and meta-heuristic search approaches together.

Aickelina and Dowsland ${ }^{5}$, Bellanti et al. ${ }^{6}$, Burke et al. ${ }^{7}$, Gutjahr and Rauner ${ }^{8}$, Beddoe et al. ${ }^{9}$, Çivril ${ }^{10}$, Bilgin et al. ${ }^{11}$, Burke et al. ${ }^{12}$ developed different models for solving real-world nurse scheduling problems and made implementation studies. Aickelina and Dowsland ${ }^{5}$ and Çivril $^{10}$ developed Genetic Algorithm models. Bellanti et al. ${ }^{6}$ developed a Greedy Algorithm based local Neighbor Search approach. Burke et al. ${ }^{7}$ developed Tabu Search algorithm. Gutjahr and Rauner ${ }^{8}$ developed Ant Koloni Algorithm for nurse scheduling for the first time. Beddoe et al. ${ }^{9}$ used CABAROST (Case Based Rostering) system which is a new model for nurse scheduling. Bilgin et al. ${ }^{11}$ developed Local Neighbor Search model. Burke et al. ${ }^{12}$ suggested a hybrid model combined Integer Programming with Shifting Neighbor Search algorithm.

Dias et al. ${ }^{12}$, Chiaramonte and Chiaramonte ${ }^{14}$, Maenhout and Vanhoucke ${ }^{15}$ improved new heuristic models for nurse scheduling problem. Cheng et al. ${ }^{16}$, Parr and Thompson ${ }^{17}$, used simulated annealing method for nurse scheduling. Maenhout and Vanhoucke ${ }^{18}$ and Brucker et al. ${ }^{19}$, set new data sets to compare suggested different models. Maenhout and Vanhoucke ${ }^{20}$, Tsai and $\mathrm{Li}^{21}$ proposed various genetic algorithms in their studies for nurse scheduling. Oughalime et al. ${ }^{22}$ developed a solution model with Tabu Search heuristic. Cheang et al. $^{23}$, Causmaecker and Berghe ${ }^{24}$ made a detailed literature search examining nurse scheduling studies.

In this study, work on Nurses Scheduling Problem (NSP) was conducted. For NSP, an Artificial Bee
Colony (ABC) algorithm has been developed. In the second section of the paper, specifications of NSP have been explained in detail. In third section, artificial bee colony algorithm is introduced and description on how to tailor it to the nurse scheduling problems is given. In the fourth section experimental results have been shown. In the last part, we conclude with evaluation of results and further research.

\section{Nurse Scheduling Problems (NSP)}

With the knowledge that nurses work at so many different branches in health enterprises. In this study the nurses that work in polyclinic services are taken into consideration. Working conditions, mission and responsibilities of nurses have been established with related laws and status. Generally, nurses work 40 hours per week. Because of the obligation of working $7 / 24$, nurses become obliged to complete their weekly works within weekdays, during weekends, mornings, evenings and even at nights. This working regulation contains differences that hospital can identify itself. In this case, some enterprises determine 8 hour - 3 shift working regulation while others apply 8-hour and 16hour 2 shift system. As similar to that, nurses in one hospital can work both in day and night shifts while in another hospital they can work continuously in day or continuously at night.

Although it is needed to get the work done, flexibility of working conditions in a wrong planned place leads to inevitable psychological and physical difficulties for the workers. For example, because of the personnel insufficiency and other reasons, the remaining nurses can work overtime. In this case a 16-hour night worker starts to work again without having sufficient rest. Similar to that, although she/he doesn't want to, a nurse becomes obliged to work continuously as a night sentry. Consistency of different working structures like intern nurses and responsible nurses in the nurse crew is getting more difficult to planning studies. For this reason, nurse scheduling has been examined in a number of studies in literature. Cheang et al. ${ }^{23}$ mentioned that constraints of nurse scheduling came from nurse contracts, statutory restrictions, nurse demands and hospital specialties. They explained that some of these constraints cannot be ignored but some of them can be flexible.

It is obligated to generate a good working schedule to minimize negative effects of working conditions on 
personnel. In lots of health enterprises of our country, nurse scheduling studies has been made by responsible nurses with hand. Insufficient personnel number, specific working regulation and demands of the nurses make the scheduling problem more complicated. In this situation, a schedule that both satisfies workers demands and needs of the enterprises is hard to prepare and it becomes a time consuming task. Addition to that, although it doesn't seem as a problem formerly, reflection of relations in people to scheduling is a possible situation.

The fact that scheduling study has a dynamic nature makes the situation more difficult. Nurse schedules are prepared every week or in general, monthly. Also demands of the employees make the schedule to have to be rearranged occasionally. This repetitive workload makes the scheduling more time-consuming and an exhausting situation.

The difficulties mentioned above bottlenecks in preparing a qualified nurse scheduling, so this situation hinders service quality. Usage of computer based models in nurse scheduling problems is very important to create schedules that make possible both qualified service and time advantage. There are several models for the nurse scheduling suggested in the literature. Cheang et al. ${ }^{23}$, explain that a general nurse scheduling problems can be defined as one of the Nurse-day, nurse- task (nurse - time intervals) or nurse-shift type models.

Nurse-Day structure is defined as a two dimensioned task list. According to that decision variable is determined for a nurse as $v_{i, j}$. In this definition $1 \leq i \leq N$ is nurse number, $1 \leq j \leq P$ is day number in planning term. $V_{i, j}$ variable mentions that will be work at that day or not. At the same time shift number can be change, shifts can be work in a day created generally in literature as morning(A), noon(P) and night(N). Notworking situation generally get values as following: using permission $(\mathrm{O})$, not coming but finding someone else instead (CO-compensation of), public holiday ( $\mathrm{PH})$ and values etc. In some studies, problem's complexity is reduced a bit by defining one type value for notworking situation. For $0-1$ models $v_{i, j}$ decision variable can be specified as $v_{i, j, k}$. In this case $1 \leq k \leq Z$ value will show shift type number. So when $v_{i, j, k}$ value equals to 0 it will be understood that $i$ nurse is not working at $j$ day $k$. shift, when it is equal to 1 she/he will be working. Nurse- Task Structure model is similar to Nurse-Day model. Decision variable for every single shift is defined as $v_{i, s}$.In this definition $1 \leq i \leq N$ shows nurse number and $1 \leq s \leq Z$ shows task number in scheduling period. One difference between these two models is that nurse-task shift definition doesn't have to fit day so it can start in any time of day and finish in other day.

Nurse-Shift Model Structure has a different form from two the models described above. Decision variable is defined as $v_{i, p}$ in this model. In this definition while $1 \leq i \leq N$ shows nurse number, $1 \leq p \leq M$ shows shift model number. In addition to that, every single shift model shows the works that will make by a nurse through a planning term. In this type of problems if $i$. nurse works in $p$. shift type, decision variable gets value 1; else it gets 0 value.

\subsection{Constraints used}

When the literature is investigated, the major problem in nurse scheduling sector is found to exist when comparison of proposed model with the previous works is made. In the study by Maenhout and Vanhoucke ${ }^{18}$, it was found that problem definition and modeling in their study are completely different from the ones found in literature, and that it is difficult to make comparisons of the proposed periods due to the fact that every hospital has its own characteristic features and procedures hence existence of differences. Apart from that, it was found that the exact and flexible constraints investigated are of a diverse types and that it is possible to take into account the constraints of different functions. The study also found that the above explained issues clarify the reason as to why the nurse scheduling studies have been dealt with differently in literature and that wide solution procedures have been proposed.

In the literature study by Ref. 23, the researchers grouped the exact and flexible constrains, often used in nurse scheduling under certain titles and made the following comments;

1. Nurse working hours (minimum or maximum working time)

2. Successive working within same shift (at least, at most or at specified amount) 
3. Number of successive working days or shifts (at least, at most or at specified amount)

4. Nurse education level and specialization area

5. Nurse demands and priorities

6. Nurses' vacation days (minimum, maximum, or successive resting days)

7. Spare times in between shifts ( minimum value)

8. Shift type promotions (maximum shift type, amount needed for every shift en)

9. Vacation days

10. Working on weekends (e.g. no working over the whole weekend)

11. Constrains related to nurse group or type (like some nurses can never work at the same time)

12. Shift model constraints

13. Old records (promotion status on a previous schedule)

14. Short and long term demands out of planning phase (e.g. a daily assignment to a shift)

15. Valid constraints throughout the shift (like no working on two shifts at the same time)

16. The need of a nurse for any shift (minimum, maximum or specified number)

In this study, the grouping specified in the study of Cheang et $\mathrm{al}^{23}$ has been taken consideration based on 1 , $5,6,7,10,12,13,15,16$ constraint types.

\subsection{Evaluation function}

In intuitional methods applied for nurse scheduling problem, the least penalized schedule is chosen as a solution by punishing an unwanted event. For this reason, it is necessary to specify penalty points for situations deemed as constraints. Based on this, in case of unwanted event, it is then punished by multiplying it with a specified constant.

When determining the punishment constants, the study conducted by Ref. 3 was taken into account. For unwanted situations known as hard constrains, constant values ranging between 500 and 1000 were selected whereas situations that could be allowed to occur also termed as soft constrain, the constant values employed were varying between 50 and 150 .

Another unwanted situation that needs to be taken into account is the constraints that appear more than once which is worse than occurring once. For this reason, constants for these situations increase exponentially rather than linearly. Equal distributed constraint of extra working hours can be given as an example. According to this, if the difference of extra working hours of two nurses is 1 , then penalty value is calculated by multiplying penalty constant by 1 whereas the penalty constant is multiplied by 4 if the difference is 2 .

\subsection{Schedule feasibility}

In order for the established schedule to be suitably accepted, it is necessary that the schedule covers all needs of the department. An example of the nurse demands is shown in Table 1. As seen from the table, the demand inputs have been set on the basis of three shifts as $8^{*} 16,16^{*} 24$ and $24 * 8$. In order to meet these demands, the nurses can work on one of these shifts: $8 * 16,8 * 24,16 * 24,16 * 8$ and $24 * 8$. If a nurse works at shift $16 * 8$, for instance, she will have covered demands from both shift $16^{*} 24$ and shift $24 * 8$.

In the conducted study, the model formed, first distributes all the demands to the nurses randomly, then it runs the Artificial Bee Colony Algorithm to improve its solution quality based on exact and flexible constraints. When the algorithm tries to improve the solution quality, it designates status by checking the statuses that are contrary to the suitable solution status and in this way; new schedules are formed without impairing the suitability of the existing schedule.

\section{Artificial Bee Colony (ABC) Algorithm}

$\mathrm{ABC}$ algorithm is one of heuristic methods that started improving in the latest years. As in other colony algorithms, basic logic of the method is to get benefit of property in solving the encountering problems about food finding of creatures living as colony in a minimum time interval with a good coordination although being in complicated and crowded structure. ABC algorithm is a model trying to imitate natural properties of bees used when they look for food.

\subsection{Working logic of artificial bee colony algorithms}

Basic logic of the $\mathrm{ABC}$ algorithm is to prove feasible solution in a short time period and prevent from hanging local optima making search for more than one solution at the same time with a good neighbor search. With this thought every solution point is defined as a bee. After that with having basis of strategy about transporting most productive and easy food to the hive by bees in their natural life, a trial in finding the most profitable point is made. 
Table 1. Sample of a weekly nurse demands.

\begin{tabular}{lllllllll}
\hline & Monday & Tuesday & Wednesday & Thursday & Friday & Saturday & Sunday \\
\hline Shifts & 8-16(Day) & 4 & 4 & 4 & 4 & 4 & 2 & 2 \\
& 16-24(Night) & 3 & 3 & 3 & 3 & 3 & 2 & 2 \\
& 24-8(Night) & 2 & 2 & 2 & 2 & 2 & 2 & 2 \\
\hline
\end{tabular}

Examining widely interaction process between nature and bees will be beneficial to fully understand the logic of algorithm. Baykasoğlu et al. ${ }^{25}$ examined this process in their study in two components: food sources and foragers as follows. (Ref. 25);

- Food Sources; Changes according to different parameters like resource values; distance to the hive, quality of nectar and ability of extrication level of nectar.

- Forager Bees;

- Unemployed foragers; bees without any knowledge on food sources. These bees can search new sources of food as scout bees or reach a food source by following other bees

- Employed foragers; when the unemployed bee finds and exploits the food source, it will rise to be an employed forager. These bees return to the hive with a little nectar and empty it to the hive. After that they inform the rest of the bees in the hive about the amount of the nectar.

- Experienced foragers; these bees direct the colony by using historical information about the places and quality of food resources.

An experiment to observe the way the colony makes selection among nectar sources was conducted by Ref. 26. Two nectar sources were placed close to the colony, one at 400 meters south and the other at 400 meters north of the hive. 12 bees were trained to head towards the north while 15 bees were trained to move to the south side. The sources were formed at different qualities where the south source was made better than the one at north. At noon, the sources were exchanged, where the south source was placed on the north and vice versa. In the other morning, their places were reversed again and at noon they were changed again. The experimental observation indicated that the number of bees at the low quality source remained low while the number of bees moving to the quality source increased. When the sources were changed, the direction of the bees also changed. Movement of bees based on the changing locations of the sources is shown on Figure 1.

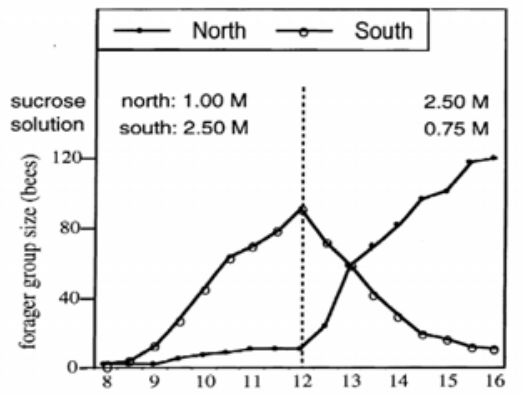

Fig. 1. Selection in between nectar sources done by the colony (Ref. 26)

The reason for superiority of $\mathrm{ABC}$ is the parallelism it uses during the decision phase. This is due to the fact that many bees move at the same direction at the same time while communicating with each other in order to solve the problem at hand in the most effective way possible.

When the existing studies in literature are investigated, it is found that apart from minor changes and some increments, the $\mathrm{ABC}$ based models formed possess the below mentioned trends in general. (Ref. 25);

(i) Define Parameters

(ii) Establish initial solutions

(iii) Calculate suitability value of each bee

(iv) Determine scout bees and form follower bees under every scout bee

(v) Compare every scout bee with its follower bees

(vi) Replace the follower bee that is better than scout bee with the scout bee

(vii) Repeat steps 3-6 until the required iteration number is reached 


\subsection{Adaptation of ABC algorithm for NSP}

Using the parameters described below, $\mathrm{ABC}$ algorithm can be modeled for NSP (Ref. 27);

B : Number of initial bees,

L : Number of scout bees,

$\mathrm{T} \quad$ : Number of follower,

$\mathrm{n} \quad$ : Number of nurses,

$\mathrm{m}$ : Number of days,

o : Number of shifts,

Z : Number of situation needed to be punished.

$\mathrm{PB}_{\mathrm{b}} \quad$ : Initial bees in population $\{\mathrm{b}=1,2, \ldots, \mathrm{B}\}$

$\mathrm{SB}_{l} \quad$ : Scout bees in population. $\{\mathrm{l}=1,2, \ldots, \mathrm{L}\}$

$\mathrm{FB}_{\mathrm{lt}} \quad$ : Follower bee of $l$. leader bee. $\{\mathrm{t}=1,2, \ldots, \mathrm{T}\}$

$\mathrm{PBP}_{\mathrm{b}}$ : Punishment points of initial bees.

$\{\mathrm{b}=1,2, \ldots, \mathrm{B}\}$

$S B P_{l}$ : Punishment points of scout bees.

$\{1=1,2, \ldots, L\}$

FBP $_{\mathrm{lt}} \quad$ : Punishment points of $l$ leader bee's follower $\{\mathrm{t}=1,2, \ldots, \mathrm{T}\}$

$\mathrm{N}_{\mathrm{i}} \quad$ : Nurses. $\{\mathrm{i}=1,2, \ldots, \mathrm{n}\}$

$\mathrm{D}_{\mathrm{j}} \quad$ : Days. $\{\mathrm{j}=1,2, \ldots, \mathrm{m}\}$

$\mathrm{S}_{\mathrm{k}} \quad$ : Shifts. $\{\mathrm{k}=1,2, \ldots, \mathrm{o}\}$

$\mathrm{P}_{\mathrm{i}} \quad$ : Punishment points of nurses. $\{\mathrm{i}=1,2, \ldots, \mathrm{n}\}$

$\mathrm{C}_{\mathrm{z}} \quad$ : Punishment coefficient of situations

$\{\mathrm{z}=1,2, \ldots, \mathrm{Z}\}$

$\mathrm{CC}_{\mathrm{z}} \quad$ : Counts of appeared situations needed to be punished,

$\mathrm{x}_{\mathrm{ijk}}$ : Reassignment situation of nurses. $\{\mathrm{i}=1,2, \ldots, \mathrm{n}\}$,

$\mathrm{F}_{\mathrm{NS}}() \quad$ : Neighbor searching function.

Processing steps of the developed algorithm by using these parameters are as shown below; 3.2.1. Forming the bees randomly for initial
solution;

Every bee indicates $P B_{h}=\left[N_{i}\right]_{n}$ series formed by $\mathrm{n}$ nurses. And $N i=\left[X_{i j k}\right]_{n X\left(0^{*} m\right)}$ series has been defined for every nurse. The index $X_{i j k}$ shows $i$. nurse working (or not working) on $j$. day and at $k$. shift.

\subsubsection{Calculating every bee's suitability value;}

The suitability value for each bee is obtained from punishment values of that particular bee. And the bee's punishment value is calculated from the total punishment values of the nurses forming that bee. The nurses' punishment values are calculated as products of punishment coefficient of a given unwanted situation and the number of exits belonging to that situation. "Eq. (1)" and "Eq. (2)" respectively, show bee punishment and nurse punishment.

$$
\begin{gathered}
P B P_{b}=\sum_{i=1}^{n} P_{i} \quad\{\mathrm{~b}=1,2, \ldots, \mathrm{B}\} \\
P_{i}=\sum_{Z=1}^{Z} C_{z} x C C_{z} \quad\{\mathrm{i}=1,2, \ldots, \mathrm{n}\}
\end{gathered}
$$

\subsubsection{Defining scout bees;}

Bees formed as initial solution are arranged in ascending order based on calculated punishment values. Then, the first $\mathrm{L}$ bees are termed as scout bees. $\left(\mathrm{SB}_{1}, \mathrm{SB}_{2}, \ldots, \mathrm{SB}_{\mathrm{L}}=\mathrm{PB}_{1}, \mathrm{~PB}_{2}, \ldots \mathrm{PB} \mathrm{PB}_{\mathrm{L}}\left\{\mathrm{PBP}_{1}<\mathrm{PBP}_{2}<\right.\right.$ $\left.\ldots<\mathrm{PBP}_{\mathrm{B}}\right\}, \quad \mathrm{SBP}_{1}, \mathrm{SBP}_{2}, \ldots, \mathrm{SBP}_{\mathrm{T}}=\mathrm{PBP}_{1}$, $\left.\mathrm{PBP}_{2}, \ldots, \mathrm{PBP}_{\mathrm{T}}\left\{\mathrm{PBP}_{1}<\mathrm{PBP}_{2}<\ldots<\mathrm{PBP}_{\mathrm{B}}\right\}\right)$

\subsubsection{Neighbor search to define follower bees of scout bees;}

Follower bees are first grouped together with the scout bees they follow, "Eq. (3)", then by applying the neighbor finding function "Eq. (4)", the scout bees are brought to neighbor status.

$$
\begin{gathered}
F B_{l t}=S B_{l} \quad \forall_{t, l} \\
F B_{l t}=F_{N S}\left(F B_{l t}\right) \forall_{t, l}
\end{gathered}
$$

\subsubsection{Calculating suitability values of follower bees;}

The suitability value of every bee is calculated from the punishment value of that bee. The method used in calculating bees' punishment, this time is used for the followers. ("Eq. (5)")

$$
F B P_{l t}=\sum_{i=1}^{n} P_{i} \quad \forall_{t, l}
$$

\subsubsection{Comparing the scout and follower bees;}

In this step each scout bee is compared with its follower bees and if a follower bee is better than the scout bee, then $\left(F B P_{1 t}<S B P_{l}\{t=1,2, \ldots, \mathrm{T}\} \quad \forall_{l}\right)$ the follower bee is defined as the scout bee.

The algorithm is prolonged in this way until a required condition is reached. When the stopping criterion is reached the best scout bee is accepted as the result. 


\subsection{Literature studies on artificial bee colony algorithm}

Studies on ABC have recently increased, being used for the purpose of obtaining suitable solutions for many problems in various sectors. In their study, Nakrani and Tovey $^{28}$ developed a new model by making use of similarities in problems encountered by bees when they collect nectar and those experienced by internet presenters. They compared the effectiveness of the new model with the Greedy algorithm. Yang ${ }^{29}$, investigated the use of $\mathrm{ABC}$ function optimization in solving problems and its comparison with Genetic Algorithm. Baykasoğlu et al. $^{25}$ tested the $\mathrm{ABC}$ to hawk problems and presented its successfulness especially for small and medium sized problems. Dehuri et al. ${ }^{30}$ used ABC for the multiple campaigns assignment problem. They compared the proposed model with the Random and Independent methods. In the Ref. 31, $\mathrm{ABC}$ was developed for solving Assignment Problems. In the study, the effects of shifting, changing, double shifting and subtraction chain neighborhood structures on the performance of $\mathrm{ABC}$ were studied. Other researchers are Lara et al. ${ }^{32}$ whose study concentrated on the use of $\mathrm{ABC}$ on "School Time Scheduling". Davidovic et al." tried to find a solution to the problem of establishing an independent static schedule by making use of $\mathrm{ABC}$. Özbakır et al. $^{34}$ studied the performance of ABC's Advanced Assignment Problems where; beside small and medium sized problems, large sized problems were also measured and comparison with the existing studies in the literature was made. The study by Kashani et al. $^{35}$ proposed the use of $\mathrm{ABC}$ for the assignment scheduling problem in the distribution system and they showed that the model is better than the Genetic Algorithm based models.

Detailed literature studies on ABC models can also be found from the studies of Kaur and $\mathrm{Goyal}^{36}$, Teodorovic $^{37}$, Suri and Snehlata ${ }^{38}$. The success of ABC in achieving solutions to optimization problems is proved by the literature studies cited on the topic, so far. However; when the literature is investigated, it is found that there is no substantial study conducted on $\mathrm{ABC}$ with the nurse scheduling problems in mind.

\section{Case Study}

The developed $\mathrm{ABC}$ algorithm was applied on five different departments of Karadeniz Technical University Research Hospital under different conditions and its performance was then evaluated.

Arrangement of the nurses working schedule on the shifts at different departments was made by the responsible nurses on duty at the hospital. In this way, it is possible to achieve a more flexible working structure. This flexibility provides a more efficient use of the man power. Every nurse in each hospital department is appointed by the hospital management and only works on day shifts during week days. After the schedules developed by responsible nurses are approved by the hospital management, they are put into effects.

Responsible nurses prepare schedules for their own departments with hand, print them out on computers and transfer them for service works. When the schedules are drafted, efforts are made to make sure that nurses' demands and work leaves are taken into account. Besides this, compulsory and flexible constraints are considered too.

The number of nurses for selected departments varied between 6 and 13. These numbers are specified by the hospital management based on the work density in respective sections.

Generally; the nurses work on 8-16, 16-24, 24-8, 8-24 or $16-8$ shifts. Beside this, when the details given in Table 3 are studied, it is found that two of the departments where the applications were made seem to want to work on only 8-16 and 16-8 shifts and three of them are on 8-16, 16-24, 8-24 and 16-8 shifts. Based on the tenth exact constraint given in Table 4 , the model developed tries to prevent the departments from working outside their respective assigned shifts by punishing the shifts appointments. In this case, if a nurse in the physical therapy department is assigned the 24-8 shift or if a nurse in the schedule of pediatric department is assigned to one of the $16-24,8-24$ or $24-8$ shifts, then the nurse is punished.

Nurse shift schedules in the existing hospitals are drafted weekly, by the nurse on duty in a particular department. Similarly; effort is generally made to equally, distribute the nurses' night shifts, overtimes and week-end works within a four-week period. The 


\section{K. Buyukozkan, A. Sarucan}

developed algorithm drafts the schedule compatible to this system and within the one month period, it also takes previous weeks' schedules into consideration. In order to determine the constraints to be dealt with and how will they affect the problem in this study, the work Ref. 3 was investigated and responsible nurses working at the hospital were also contacted to have their views on the matter. The constraints used in the model, their weight values and evaluation of their punishments are given in Table 2.

Application trial of the system was carried out in different departments and under five different working conditions common to all the departments; where the performance of the proposed algorithm was evaluated. Characteristic features and special limitations of the departments where the application was made are given in Table 3. Information showing the day and number of nurses working at which shifts is found on Table 4 .

When the Table 3 is studied, it is seen that, for every department the first nurse is the responsible nurse for that department. The responsible nurses have work schedules that only show that they can work in day times on weekdays. That's why these nurses are assigned works on day shifts within weekdays while weekends and night shifts are for closing the day.

Therefore; scheduling these nurses as required is achieved with the exact constraints of number four or seven. Similar to this, situations at which the nurses want (or don't want) to work are suitably achieved with the fourth, seventh and ninth constraints. The types of shifts applied for every shift are also shown on Table 3 . To make sure that the assignments made are compatible with these shift types, the number ten exact constraint is used.

\subsection{Solution of the problem with ABC algorithm}

First of all, a random initial solution is established based on the number of the bees in the program. When the initial solution is established, user demands and the number of existing nurses are taken into account, and then all the demands are randomly assigned to the nurses. The program establishes initial solution by executing the following algorithm steps randomly up to the number of bees.

(i) Turn up to the initial number of bees

(ii) Turn until all the demands are met

(iii) Choose one day at random

(iv) Choose a shift at random

(v) Choose a nurse at random

(vi) If the demand of a chosen shift on that day is not met and if the chosen nurse has not been assigned that shift before, then assign the chosen demand to the chosen nurse, otherwise don't assign.

(vii) If the criterion to stop is achieved, then stop, save the schedule established. Turn to the $2^{\text {nd }}$ step.

(viii) If all the bees have been formed, then stop.

After producing the initial solution, the suitability value of every bee is calculated and then the bees are arranged from small to large ones based on their suitability values. The best bees are selected up to the number of the scout bees, and then the rest bees are erased. On Table 2, exact and soft constraints and their respective punishment weights are shown. 
Bee Colony for Nurse Scheduling

Tablo 2. Constraints and penalty points.

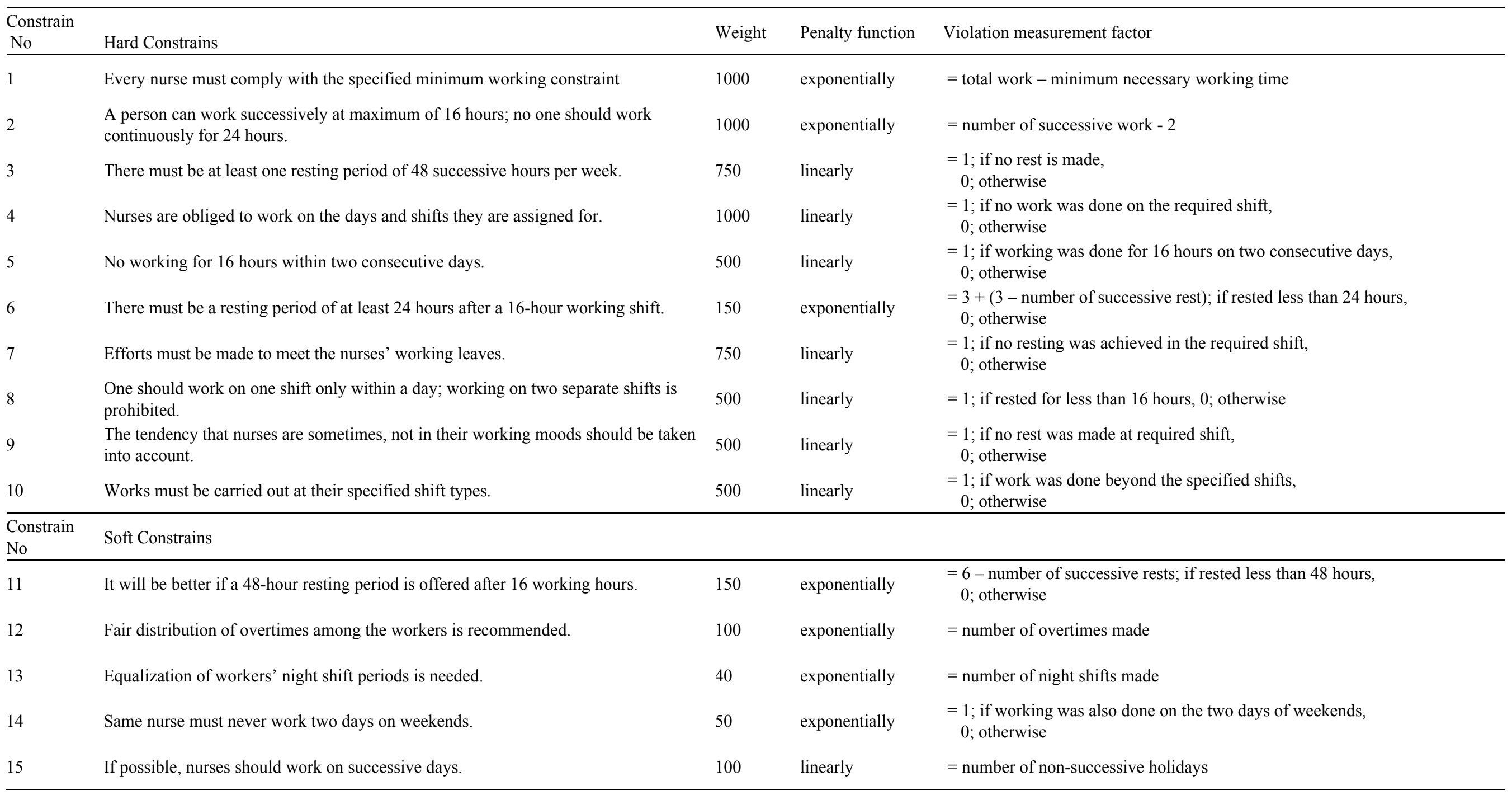


Table 3. Department details and special cases.

\begin{tabular}{|c|c|c|c|c|}
\hline Department & $\begin{array}{l}\text { Planning } \\
\text { period }\end{array}$ & $\begin{array}{l}\text { Number of } \\
\text { nurses }\end{array}$ & Shift type & Nurse requests and preferences \\
\hline $\begin{array}{l}\text { Plastic } \\
\text { Surgery }\end{array}$ & $\begin{array}{l}\text { 05 March - } 01 \\
\text { April } 2012\end{array}$ & 7 & $\begin{array}{l}8 * 16 \\
16 * 8 \\
8 * 24 \\
16 * 24\end{array}$ & $\begin{array}{l}\text { 1st nurse, the responsible nurse } \\
2 \text { nd nurse will be on duty on Saturdays of the } 1 \text { st and } 2 \text { nd week }\end{array}$ \\
\hline & & & & 1 st nurse, the responsible nurse \\
\hline $\begin{array}{l}\text { Obstetrics } \\
\text { and } \\
\text { Gynecology }\end{array}$ & $\begin{array}{l}05 \text { November - } \\
02 \text { December } \\
2012\end{array}$ & 6 & $\begin{array}{l}8 * 16 \\
16 * 8\end{array}$ & $\begin{array}{l}\text { 4th nurse wants to work at night in the weekdays and at day times on weekends } \\
3 \text { rd nurse wants to work on Saturday in the } 1 \text { st week, on Wednesday and Sunday in } \\
\text { the } 2 \text { nd week, on Friday in the } 3 \text { rd week, on Tuesday and Sunday in the } 4 \text { th week at } \\
16 * 8 \text { shifts. }\end{array}$ \\
\hline Pediatrics & $\begin{array}{l}01 \text { October }-28 \\
\text { October } 2012\end{array}$ & & $\begin{array}{l}8 * 16 \\
16 * 8\end{array}$ & $\begin{array}{l}\text { 1st nurse, the responsible nurse } \\
2 \text { nd nurse will work on day shifts in the first three weeks, and at } 16 * 8 \text { shift on } \\
\text { Friday in the } 4 \text { th week } \\
2 \text { nd nurse is off duty on Wednesday, Thursday and Friday of the } 1 \text { st week. } \\
4 \text { th week, all workers will work } 16 \text { hours less than normal due to festival holiday } \\
6 \text { th nurse is off duty until Saturday of the } 4 \text { th week. }\end{array}$ \\
\hline Oncology & $\begin{array}{l}03 \text { September - } \\
30 \text { September } \\
2012\end{array}$ & 13 & $\begin{array}{l}8 * 16 \\
16 * 8 \\
8 * 24 \\
16 * 24\end{array}$ & $\begin{array}{l}\text { 1st nurse, the responsible nurse } \\
\text { 2nd, 3rd and 5th nurses shall work on day times during weekdays } \\
\text { 2nd nurse is on the 4th week leave. } \\
6 \text { th nurse spends her annual leave throughout four-week period } \\
8 \text { th nurse is on her first two weeks of the annual leave } \\
11 \text { th nurse is on annual leave from Monday of the second week up to Wednesday of } \\
\text { the 3rd week. } \\
\text { 12th nurse is on the third week of her annual leave }\end{array}$ \\
\hline
\end{tabular}

1 st nurse, the responsible nurse

2 nd nurse wants to work twice at the $16 * 8$ shift on weekdays

3 rd nurse is on annual leave with the exception of Wednesday of the second week 7 th nurse works 32 hours a week and can only work at the $8 * 16$ shift.

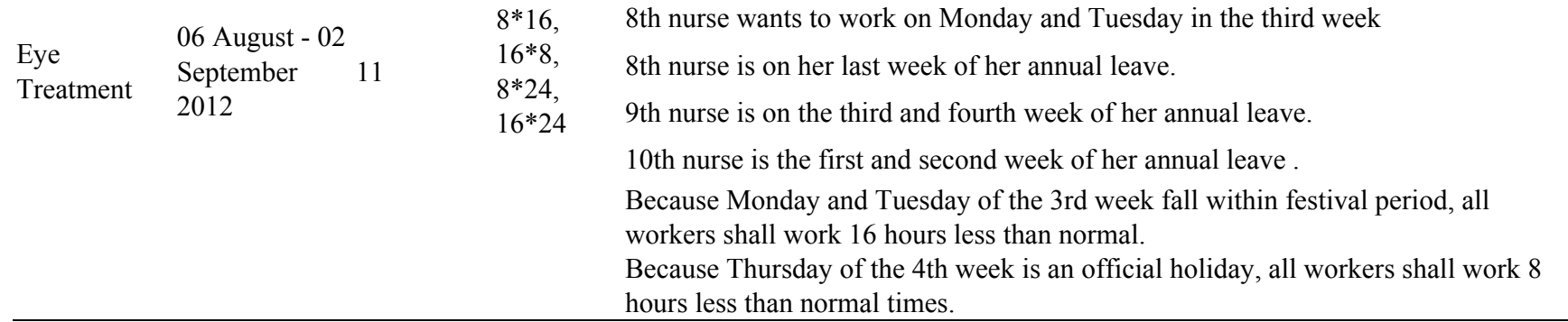


Table 4. Nurse demands for the departments.

\begin{tabular}{|c|c|c|c|c|c|c|c|c|c|c|c|c|c|c|c|c|c|c|c|c|c|c|c|c|c|c|c|c|}
\hline \multirow{2}{*}{ Department $\mid$ Days } & \multicolumn{7}{|c|}{ First Week } & \multicolumn{7}{|c|}{ Second Week } & \multicolumn{7}{|c|}{ Third Weed } & \multicolumn{7}{|c|}{ Fourth Week } \\
\hline & Mo & $\mathrm{Tu}$ & $\mathrm{We}$ & Th & $\mathrm{Fr}$ & $\mathrm{Sa}$ & $\mathrm{Su}$ & Mo & $\mathrm{Tu}$ & We & Th & $\mathrm{Fr}$ & $\mathrm{Sa}$ & $\mathrm{Su}$ & Mo & $\mathrm{Tu}$ & We & $\mathrm{Th}$ & $\mathrm{Fr}$ & $\mathrm{Sa}$ & $\mathrm{Su}$ & Mo & $\mathrm{Tu}$ & We & Th & $\mathrm{Fr}$ & $\mathrm{Sa}$ & $\mathrm{Su}$ \\
\hline \multirow{3}{*}{ Plastic Surgery } & 3 & 3 & 3 & 3 & 3 & 1 & 1 & 3 & 3 & 3 & 3 & 3 & 1 & 1 & 3 & 3 & 3 & 3 & 3 & 1 & 1 & 3 & 3 & 3 & 3 & 3 & 1 & 1 \\
\hline & 2 & 2 & 2 & 1 & 2 & 1 & 1 & 1 & 2 & 2 & 2 & 2 & 1 & 1 & 1 & 2 & 2 & 2 & 2 & 1 & 1 & 1 & 2 & 2 & 2 & 2 & 1 & 1 \\
\hline & 1 & 1 & 1 & 1 & 1 & 1 & 1 & 1 & 1 & 1 & 1 & 1 & 1 & 1 & 1 & 1 & 1 & 1 & 1 & 1 & 1 & 1 & 1 & 1 & 1 & 1 & 1 & 1 \\
\hline \multirow{3}{*}{$\begin{array}{l}\text { Obstetrics and } \\
\text { Gynecology }\end{array}$} & 3 & 3 & 3 & 2 & 3 & 1 & 1 & 3 & 3 & 3 & 3 & 2 & 1 & 1 & 3 & 3 & 3 & 3 & 2 & 1 & 1 & 3 & 3 & 3 & 3 & 2 & 1 & 1 \\
\hline & 1 & 1 & 1 & 1 & 1 & 1 & 1 & 1 & 1 & 1 & 1 & 1 & 1 & 1 & 1 & 1 & 1 & 1 & 1 & 1 & 1 & 1 & 1 & 1 & 1 & 1 & 1 & 1 \\
\hline & 1 & 1 & 1 & 1 & 1 & 1 & 1 & 1 & 1 & 1 & 1 & 1 & 1 & 1 & 1 & 1 & 1 & 1 & 1 & 1 & 1 & 1 & 1 & 1 & 1 & 1 & 1 & 1 \\
\hline \multirow{3}{*}{ Pediatrics } & 3 & 3 & 2 & 2 & 2 & 1 & 1 & 3 & 3 & 3 & 3 & 2 & 1 & 1 & 3 & 3 & 3 & 3 & 2 & 1 & 1 & 3 & 3 & 1 & 1 & 2 & 1 & 1 \\
\hline & 1 & 1 & 1 & 1 & 1 & 1 & 1 & 1 & 1 & 1 & 1 & 1 & 1 & 1 & 1 & 1 & 1 & 1 & 1 & 1 & 1 & 1 & 1 & 1 & 1 & 1 & 1 & 1 \\
\hline & 1 & 1 & 1 & 1 & 1 & 1 & 1 & 1 & 1 & 1 & 1 & 1 & 1 & 1 & 1 & 1 & 1 & 1 & 1 & 1 & 1 & 1 & 1 & 1 & 1 & 1 & 1 & 1 \\
\hline \multirow{3}{*}{ Oncology } & 5 & 5 & 4 & 4 & 4 & 1 & 1 & 4 & 4 & 5 & 5 & 4 & 1 & 1 & 4 & 5 & 4 & 4 & 4 & 1 & 2 & 4 & 4 & 5 & 4 & 4 & 2 & 3 \\
\hline & 2 & 2 & 3 & 3 & 3 & 2 & 2 & 2 & 2 & 2 & 2 & 3 & 2 & 2 & 2 & 2 & 2 & 2 & 2 & 2 & 2 & 2 & 2 & 3 & 2 & 3 & 2 & 2 \\
\hline & 2 & 2 & 2 & 2 & 2 & 2 & 2 & 2 & 2 & 2 & 2 & 2 & 2 & 2 & 2 & 2 & 2 & 2 & 2 & 2 & 2 & 2 & 2 & 2 & 2 & 2 & 2 & 2 \\
\hline \multirow{3}{*}{ Eye Treatment } & 3 & 3 & 3 & 3 & 3 & 2 & 2 & 4 & 3 & 4 & 4 & 3 & 2 & 1 & 1 & 1 & 4 & 3 & 3 & 3 & 2 & 3 & 3 & 3 & 2 & 3 & 1 & 1 \\
\hline & 2 & 2 & 2 & 2 & 2 & 2 & 2 & 2 & 2 & 2 & 2 & 2 & 1 & 1 & 1 & 1 & 1 & 3 & 2 & 2 & 3 & 2 & 1 & 1 & 1 & 1 & 1 & 1 \\
\hline & 2 & 2 & 1 & 1 & 2 & 1 & 2 & 2 & 2 & 2 & 2 & 2 & 1 & 1 & 1 & 1 & 1 & 3 & 1 & 2 & 2 & 1 & 1 & 1 & 1 & 1 & 1 & 1 \\
\hline
\end{tabular}


Table 5. Parameters used for the recommended ABC algorithm and their solution periods parameters.

\begin{tabular}{|c|c|c|c|c|c|c|c|c|c|}
\hline & & \multirow{2}{*}{$\begin{array}{l}\text { Number of } \\
\text { Initial bee }\end{array}$} & \multirow{2}{*}{$\begin{array}{l}\text { Number } \\
\text { of Scout } \\
\text { bees }\end{array}$} & \multirow{2}{*}{$\begin{array}{l}\text { Number of } \\
\text { Follower } \\
\text { Bees }\end{array}$} & \multirow[b]{2}{*}{ Iteration } & \multicolumn{4}{|c|}{ CPU Time (second) } \\
\hline & & & & & & $\begin{array}{l}\text { First } \\
\text { Week }\end{array}$ & Second Week & Third Weed & Fourth Week \\
\hline \multirow{5}{*}{ 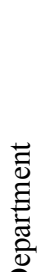 } & Plastic Surgery & 150 & 15 & 20 & 1200 & 23,68 & 25,59 & 25,63 & 26,24 \\
\hline & Obstetrics and Gynecology & 150 & 15 & 20 & 1200 & 24,98 & 25,44 & 25,75 & 25,55 \\
\hline & Pediatrics & 150 & 15 & 20 & 1200 & 25,02 & 26,86 & 26,73 & 26,59 \\
\hline & Eye Treatment & 150 & 15 & 20 & 1200 & 26,8 & 28,98 & 28,72 & 27,72 \\
\hline & Oncology & 150 & 15 & 20 & 1200 & 28,2 & 30,22 & 30,68 & 31,1 \\
\hline
\end{tabular}

In case of a situation that necessitates penalty, then by taking the data regarding that situation from Table 2 , penalty value is calculated and added onto the bee's penalty.

Penalty points are calculated in the same way both at the initial solution and during evaluation of the follower bees. The penalties of the nurses throughout a weekly schedule are summed up to obtain the bees' or followers' penalties.

Generally, the schedule obtained from the initial solution becomes in a worse condition. To improve such a schedule, neighbor finding is applied around the pioneer bees in order to establish the followers. Neighbor finding is achieved with the following algorithm steps;

(i) Turn up to the number of pioneer bees

(ii) Equalize all the follower bees to the pioneer bees

(iii) Reset the counter

(iv) Turn up to the number of follower bees

(v) Select two nurses randomly

(vi) Make one increment to the counter

(vii) Randomly choose a day

(viii) Select a shift randomly

(ix) Randomly select two nurses

(x) Change the selected shifts for the selected nurses, calculate the follower penalty

(xi) If the new status is better or the counter $=5$, then save the follower and increase the number of follower by one. Otherwise return to step 6 .

(xii) If the number of followers is reached, increase the number of pioneer by one and return to the $2^{\text {nd }}$ step (xiii) If the number of pioneer bees is reached, then compare every pioneer bee with its follower bee; designate a good follower bee as a pioneer bee.
After determining bee followers, the bees are compared with respective follower bees and the best bee is chosen as the pioneer bee. After specifying every pioneer bee in this manner, iteration becomes accomplished. Then the loop starts again and the algorithm runs until the required number of iterations is reached. The stopping condition in this study has been defined as the number of iterations. In order to determine the correct number of iterations, the program was run several times with different types of problems.

The model formed has been designed basically for establishing weekly schedules. When the program is run once, the first week solution will have been established. Beside this, the model forms a four week schedule by taking the previous weeks' schedules into consideration. In this way, schedules for a four-week period will have correctly been formed.

\subsection{The software developed for the problem}

To achieve solution to the nurse scheduling problem a user interactive program was prepared on Visual Studio C \# software $^{27}$. A useful user guide interface that enables the program user to enter necessary data was formed. While most studies in literature are only capable of offering solutions to certain specific shift models, the developed program in this study allows the user to select any required shift type from the user interface. In addition, the program has been designed in such a way that, through its interface, it allows entrance of penalty values for details such as the number of personnel, demand values, exact and flexible constraints. With these features, the developed program provides a good opportunity for making changes, easily, to the characteristic specifications of the problem. This 
flexible feature of the program provides a room for applications with different hospitals and a diverse range of the departments at those hospitals.

At Karadeniz Technical University, Faculty of Medicine, where this study was conducted, the scheduling programs are carried out by responsible personnel of every department. This forms a structure that enables more accurate and quick decision on workers special demands like workers leaves, types of works etc. With the help of its flexible feature, the study enables separate formation of schedules for every department and simplifies their control by the responsible personnel of these departments.

\subsection{Program print outs and evaluation}

The parameters and solution periods used for the $\mathrm{ABC}$ algorithm conducted for the hospital departments are given in Table 5. In order to determine suitable parametric values, the program was run several times.

When the table (Table 5) is studied it is found that same parameter values are sufficient for all the departments. This shows that the parameters used were chosen correctly. When the processing time is investigated it is seen that the program used between 23 and 31 seconds to establish a weekly schedule. Such a short processing time increases usability of the program in real life.

The difference between the longest and shortest processing time for a weekly schedule is about 8 seconds. This shows how insignificant the effects of tough conditions or increasing the number of personnel may be to the program. The schedules obtained from the conducted studies and the existing schedules were evaluated based on specified constraints. Table 6 shows the constraints infringing numbers for every department calculated by the developed $\mathrm{ABC}$ program. These constraints' infringing numbers are the total of values for a four-week period. As for the schedules applied by the hospital management, the constraint infringing numbers are given in Table.

When Table 3 is studied, it is seen that there is no special constraining conditions, whatsoever, for the plastic surgery department. Higher number of shifts worked at, simplifies the assigning process. Within the planning period, none of the personnel took a leave. If the demand values given in Table 4 are studied, it is observed that the available number of workers is quite sufficient to cover all the demands without necessitating them to work on overtimes. When the values for the plastic surgery department in Table 6 are studied, it is seen that the proposed algorithm sufficiently covers all the exact constraints under the given operating conditions and that 22 flexible constraints are infringed. Corresponding to this, when the values for plastic surgery given in Table 7 are investigated, it is found that, in the existing application, the third exact constraint was infringed twice whereas the sixth exact constraint was infringed once. Besides this, flexible constraints were found to be infringed eighty times. This proves that the proposed $\mathrm{ABC}$ algorithm model exhibits better performance than the conventional method provided that extreme conditions are not the case.

Investigation on values given for the second department in Table 3 reveals that this department possesses more constraining special cases than the first department does. The fact that there are only two working shifts in the department plus inclusion of special demands of the nurses in the schedule cause slight toughening of the department. Table 4 also indicates that the existing number of personnel in the second department is capable of covering the nurses' demands without having overtimes. As for the case of infringed constraints listed in Table 6, it is seen that the proposed algorithm has had only one exact constraint infringed while flexible constraints have been infringed twenty four times. Table 7 shows the values for the second department where by the existing method has undergone exact constraint infringement four times and flexible constraints sixty five times.

As for the remaining $3^{\text {rd }}, 4^{\text {th }}$ and $5^{\text {th }}$ departments, when Table 3 is studied it is found that special cases are progressively increasing and that scheduling procedures become more complex. Table 6 , shows that even under these tough conditions the proposed algorithm still exhibits better performance by maintaining all the exact constraints for the $3^{\text {rd }}$ and $5^{\text {th }}$ departments but infringing four exact constraints for the $4^{\text {th }}$ department. On the contrary, when Table 7 is investigated, it is found that in the applied schedule 3,16 and 5 exact constraints were infringed in the $3^{\text {rd }}, 4^{\text {th }}$ and $5^{\text {th }}$ departments respectively. By comparing these two situations, it is 


\section{K. Buyukozkan, A. Sarucan}

clearly seen that the proposed algorithm forms more quality schedules even under difficult conditions than the existing schedule. The result tables (Table 6 and Table 7) show that the proposed algorithm is capable of forming more improved schedules for all the five departments as compared with the normally applied system. As it is also seen from Table 6, the total of infringed exact constraints is 5 and the total number of infringed flexible constraints is 208; but the total number of exact constraints infringed in the applied schedules (Table 7) is 31 while that of the flexible constraints within that system is 457 . These results confirm that, under various operating conditions, the proposed algorithm runs effectively and establishes suitable nurse schedules in a quick manner.

Table 6. Number of infringed constraints in the schedules formed with the proposed ABC algorithm.

\begin{tabular}{|c|c|c|c|c|c|c|c|c|c|c|c|c|c|c|c|c|}
\hline \multirow{2}{*}{ No } & \multirow{2}{*}{ Department } & \multicolumn{10}{|c|}{ Hard Constraints $(1,2, \ldots, 10)$} & \multicolumn{5}{|c|}{ Soft Constraints $(11,12, \ldots, 15)$} \\
\hline & & 1 & 2 & 3 & 4 & 5 & 6 & 7 & 8 & 9 & 10 & 11 & 12 & 13 & 14 & 15 \\
\hline 1 & Plastic Surgery & 0 & 0 & 0 & 0 & 0 & 0 & 0 & 0 & 0 & 0 & 0 & 0 & 6 & 4 & 12 \\
\hline 2 & $\begin{array}{l}\text { Obstetrics and } \\
\text { Gynecology }\end{array}$ & 0 & 0 & 0 & 0 & 0 & 0 & 0 & 0 & 1 & 0 & 3 & 0 & 5 & 1 & 15 \\
\hline 3 & Pediatrics & 0 & 0 & 0 & 0 & 0 & 0 & 0 & 0 & 0 & 0 & 0 & 2 & 4 & 4 & 16 \\
\hline 4 & Eye Treatment & 0 & 0 & 0 & 0 & 0 & 0 & 1 & 1 & 0 & 2 & 15 & 3 & 9 & 6 & 23 \\
\hline 5 & Oncology & 0 & 0 & 0 & 0 & 0 & 0 & 0 & 0 & 0 & 0 & 21 & 4 & 11 & 5 & 34 \\
\hline
\end{tabular}

Table 7. Number of infringed constraints in the schedules prepared by the hospital management.

\begin{tabular}{|c|c|c|c|c|c|c|c|c|c|c|c|c|c|c|c|c|}
\hline \multirow{2}{*}{ No } & \multirow{2}{*}{ Department } & \multicolumn{10}{|c|}{ Hard Constraints $(1,2, \ldots, 10)$} & \multicolumn{5}{|c|}{ Soft Constraints $(11,12, \ldots, 15)$} \\
\hline & & 1 & 2 & 3 & 4 & 5 & 6 & 7 & 8 & 9 & 10 & 11 & 12 & 13 & 14 & 15 \\
\hline 1 & Plastic Surgery & 0 & 0 & 2 & 0 & 0 & 1 & 0 & 0 & 0 & 0 & 39 & 0 & 6 & 4 & 31 \\
\hline 2 & $\begin{array}{l}\text { Obstetrics and } \\
\text { Gynecology }\end{array}$ & 0 & 0 & 1 & 0 & 0 & 0 & 0 & 0 & 3 & 0 & 33 & 0 & 8 & 3 & 21 \\
\hline 3 & Pediatrics & 0 & 0 & 3 & 0 & 0 & 0 & 0 & 0 & 0 & 0 & 24 & 4 & 4 & 3 & 20 \\
\hline 4 & Eye Treatment & 0 & 0 & 2 & 0 & 3 & 3 & 0 & 0 & 4 & 4 & 60 & 3 & 11 & 7 & 33 \\
\hline 5 & Oncology & 0 & 0 & 1 & 0 & 2 & 2 & 0 & 0 & 0 & 0 & 83 & 4 & 15 & 6 & 35 \\
\hline
\end{tabular}

\section{Results and Suggestions}

In this study, Artificial Bee Colony (ABC) algorithm has been proposed for the Nurse Scheduling Problems (NSP) which is termed as a NP-difficult problem in literature. In order for the proposed algorithm to work a user interface model was developed on a PC by using a flexible $\mathrm{C} \#$ programming language.

This is the first study that uses $\mathrm{ABC}$ algorithm to deal with the NSP. In order to evaluate the performance of the proposed $\mathrm{ABC}$ algorithm, real data obtained from five departments of the hospital belonging to Karadeniz Technical University, Faculty of Medicine were used. Shift schedules were formed by using the data and the results obtained from the algorithm were compared with the existing applied method.

The constraints and penalty points considered during scheduling, literature studies and face to face contacts made with hospital personnel were specified based on the real situations. The obtained results indicated that algorithm exhibits improved performance under all conditions by substantially covering both exact and flexible constraints, forming more improved schedules than the existing method and that the new method is faster too. Consequently; this study has shown that ABC algorithm is a suitable method for NSP.

Future studies may include parameter analysis and hybrid methodologies to speed up the model even further and enhancing the solution quality. Moreover; the same data may be used and the proposed algorithm 
may be compared and contrasted with other intuitive methods like Genetic Algorithm, Variable Neighbor Search, and Tabu Search

\section{References}

1. C. Valouxis and E. Housos, Hybrid optimization techniques for the workshift and rest assignment of nursing personnel, Artificial Intelligence in Medicine, 20(2) (2000) 155-175.

2. E. Burke, P. Cowling, P. D. Causmaecker and G. V. Berghe, A memetic approach to the nurse rostering problem, Applied Intelligence, 15(3) (2001) 199-214.

3. E.K. Burke, T. Curtois, G. Post, R. Qu and B. Veltman, A hybrid heuristic ordering and variable neighbourhood search for the nurse rostering problem, European J. of Operational Research, 188(2) (2008) 330-341.

4. J. Li, E. K. Burke, T. Curtois, S. Petrovic and R. Qu, The falling tide algorithm: a new multi objective approach for complex workforce scheduling, Omega-Int. J. of Man. Science, 40(3) (2012) 283-293.

5. U. Aickelin and K. A. Dowsland, An indirect genetic algorithm for a nurse-scheduling problem, Computers and Operations Research, 31(5) (2004) 761-778.

6. F. Bellanti, G. Carello, F. Della Croce and R. Tadei, A greedy-based neighborhood search approach to a nurse rostering problem, European Journal of Operational Research, 153 (2004) 28-40.

7. E. K. Burke, P. Causmaecker, S. Petrovic and G. V. Berghe, Metaheuristics for handling time interval coverage constraints in nurse scheduling, Applied Artificial Intelligence, 20(9) (2006) 743-766.

8. W. J. Gutjahra and M. S. Raunerb, An ACO algorithm for a dynamic regional nurse-scheduling problem in Austria, Computers and Operations Research, 34 (2007) 642-666.

9. G. Beddoe, S. Petrovic and J. Li, A hybrid metaheuristic case-based reasoning system for nurse rostering, Journal of Scheduling, 12(2) (2009) 99-119.

10. H. Çivril, Genetic Algorithms for Nurse Scheduling Problems, M.Sc. Thesis, (Süleyman Demirel University Graduate School of Applied and Natural Science, Isparta, Turkey, 2009). (Language: Turkish).

11. B. Bilgin, P. Causmaecker, B. Rossie and G. V. Berghe, Local search neighbourhoods for dealing with a novel nurse rostering model, Annals of Operations Research, 194(1) (2012) 33-57.

12. E. K. Burke, J. Li and R. Qu, A hybrid model of integer programming and variable neighbourhood search for highly-constrained nurse rostering problems, European J. of Operational Research, 203(2) (2010) 484-493.

13. T. M. Dias, D. F. Ferber, C. C. Souza and A. V. Moura, Constructing nurse schedules at large hospitals,
International Transactions in Operational Research, 10 (2003) 245-265.

14. M. V. Chiaramonte and L. M. Chiaramonte, An agentbased nurse rostering system under minimal staffing conditions, International Journal Production Economics, 114(2) (2008) 697-713.

15. B. Maenhout and M. Vanhoucke, An evolutionary approach for the nurse rerostering problem, Computers and Operations Research, 38(10) (2011) 1400-1411.

16. M. Cheng, H. I. Ozaku, N. Kuwahara, K. Kogure and J. Ota, Simulated annealing algorithm for daily nursing care scheduling problem, Proc. 3rd Annual IEEE Conference on Automation Science and Engineering, (Scottsdale, AZ, USA, 2007), pp. 507-512.

17. D. Parr and J. M. Thompson, Solving the multi-objective nurse scheduling problem with a weighted cost function, Annals of Operations Research, 155(1) (2007) 279-288.

18. B. Maenhout and M. Vanhoucke, An electromagnetic meta-heuristic for the nurse scheduling problem, Journal of Heuristics, 13(4) (2007) 359-385.

19. P. Brucker, E. K. Burke, T. Curtois, R. Qu and G. V. Berghe, A shift sequence based approach for nurse scheduling and a new Benchmark dataset, Journal of Heuristics, 16(4) (2010) 559-573.

20. B. Maenhout and M. Vanhoucke, Comparison and hybridization of crossover operators for the nurse scheduling problem, Annals of Operations Research, 159(1) (2008) 333-353.

21. C. Tsai and S. H. A. Li, A two-stage modeling with genetic algorithms for the nurse scheduling problem, Expert Systems with Applications, 36 (2009) 9506-9512.

22. A. Oughalime, W. R. İsmail and L. C. Yeun, A tabu search approach to the nurse scheduling problem, International Symposium on Information Technology, 1 (2008) pp. 1-7.

23. B. Cheang, H. Li, A. Lim and B. Rodrigues, Nurse rostering problems-a bibliographic survey, European Journal of Operational Research, 151 (2003) 447-460,

24. P. Causmaecker and G. V. Berghe, A categorisation of nurse rostering problems, J. Sched, 14(1) (2010) 3-16.

25. A. Baykasoğlu, L. Özbakır and P. Tapkan, Swarm intelligence: focus on ant and particle swarm optimization, Edited by Felix T. S. Chan and Manoj Kumar Tiwari, I-Tech Education and Publishing, 1th edn. (Vienna, Austria, 2007), pp. 114-144.

26. T. D. Seeley, S. Camazine and J. Sneyd, Collective decision-making in honey bees: how colonies choose among nectar sources, Behav Ecol Sociobiol, 28 (1991) 277-290.

27. K. Buyukozkan, A Bee Colony Algorithm For Nurse Scheduling Problem And An Application In A Health Service System, M.Sc. Thesis, (Selçuk University, Institute of Natural Sciences, Konya, Turkey, 2012). (Language: Turkish). 
28. S. Nakrani and C. Tovey, On honey bees and dynamic server allocation in internet hosting centers, International Society for Adaptive Behavior, 12(3-4) (2004) 223-240.

29. X. Yang, Engineering optimizations via nature-inspired virtual bee algorithms, IWINAC, (Berlin Heidelberg, 2005), pp. 317-323.

30. S. Dehuri, S. Cho and A. K. Jagadev, A multi-agent approach for multiple campaigns assignment problem, International Conference on Information Technology, (2008) pp. 24-29.

31. P. Tapkan, L. Özbakır and A. Baykasoğlu, Bees algorithm and generalized assignment problem: comparison of different neighborhood structures, $J$. Industrial Engineering, 21(2) (2008) 2-13. (in Turkish).

32. C. Lara, J. J. Flores and F. Calderon, Solving a school timetabling problem using a bee algorithm, MICAI, (Berlin Heidelberg, 2008), pp. 664-674.

33. T. Davidovic, M. Selmic and D. Teodorovic, Scheduling independent tasks: bee colony optimization approach, 17th Mediterranean Conference on Control \& Automation, (Makedonia Palace, Thessaloniki, Greece, 2009), pp. 1020-1025.

34. L. Özbakır, A. Baykasoğlu and P. Tapkan, Bees algorithm for generalized assignment problem, Applied Mathematics and Computation, 215(11) (2010) 3782 3795.

35. M. H. Kashani, M. Jamei, M. Akbari and R. M. Tayebi, Utilizing bee colony to solve task scheduling problem in distributed systems, Third International Conference on Computational Intelligence, Communication Systems and Network, (2011) pp. 298-303.

36. A. Kaur and S. Goyal, A Survey on the applications of bee colony optimization techniques, Int. J. Computer Science Eng., 3(8) (2011) 3037.

37. D. Teodorovic, T. Davidovic and M. Selmic, Bee colony optimization: the applications survey, Transactions on Computational Logic, (2011) 1-20.

38. B. Suri and Snehlata, Review of artificial bee colony algorithm to software testing, IJRRCS, 2(3) (2011) 706711. 